\title{
Update on Shunt Surgery
}

\author{
Tim R. Glowka Jörg C. Kalff Steffen Manekeller \\ Department of Surgery, University of Bonn, Bonn, Germany
}

\section{Keywords}

Portal hypertension - Portal/mesenteric vein thrombosis . Surgical portocaval shunt · Cirrhosis - Esophageal varices

\begin{abstract}
Background: Bleeding from esophagogastric varices is a lifethreatening complication from portal hypertension. It occurs in $15 \%$ of patients and has a mortality rate of $20-35 \%$. Summary: The primary therapy for variceal bleeding is medical. In cases of recurrent bleeding, a definitive therapy is required. In cases of parenchymal decompensation, liver transplantation is the causal therapy, but if liver function is preserved, portal decompression is the therapy of choice. The use of the transjugular intrahepatic portosystemic shunt (TIPS) has achieved widespread acceptance, although evidence for surgical shunts is comparable or better in patients with good hepatic reserve. The type of surgical shunt depends on the patent veins of the portomesenteric system. If total occlusion is present, a devascularization procedure might be indicated. Key Messages: Therapy, taking into account liver function, morphology of the portovenous system, and imminent liver transplantation, should be performed by an interdisciplinary team of gastroenterologists, interventional radiologists, and gastrointestinal surgeons.
\end{abstract}

\section{Introduction}

Portal hypertension $(\mathrm{PH})$ is a frequent complication of liver cirrhosis and portal/mesenteric vein thrombosis [1]. In western countries, liver cirrhosis accounts for $90 \%$ of $\mathrm{PH}$ cases, the others being mainly extrahepatic portal vein thrombosis (PVT) and idiopathic PH [2]. The most significant complication arising from $\mathrm{PH}$ is variceal bleeding (VB), which occurs in $15 \%$ of patients independently of the underlying disease [3-5]. The primary therapy for VB is medical according to the Baveno VI guidelines, and even early TIPS should be considered in patients with a high risk of treatment failure [6]. The 6-week mortality after VB is still 20-35\% [7] and rebleeding occurs in 20$30 \%$, this is why patients with VB require variceal decompression as the only effective causative therapy [8-11]. Since the introduction of the transjugular intrahepatic portosystemic shunt (TIPS) in 1988 [12], the therapy of $\mathrm{PH}$ has profoundly changed. TIPS is nowadays widely available, and the Baveno VI consensus recommends TIPS when primary therapy with nonselective $\beta$-blockers and endoscopic ligation fails (the option of a surgical shunt is not even mentioned) [6]. This has led to a significant reduction in the frequency of surgical shunt procedures (12 times more TIPS than surgical shunts were deployed in the USA in 2002-2005 [13]). 
The reduced involvement of gastrointestinal surgeons in the therapy of $\mathrm{PH}$ has led to a comprehensive decline in the expertise in portocaval shunt surgery in many surgical departments [13-15]. Despite the widespread acceptance of TIPS, its superiority over surgical shunting techniques has never been shown [11, 16-19]. Surgical shunts perform better in terms of shunt patency, long-term survival, and economic aspects [1]. One significant objection in most studies comparing TIPS and surgical shunts is the use of uncovered stents, but even when polytetrafluoroethylene (PTFE)-covered stents are used, the surgical shunt shows better results [20]. The correct therapy algorithm for variceal decompression, taking into account liver function, rebleeding frequency, long-term outcome, graft patency, and cost-effectiveness, should be chosen by an interdisciplinary team with experience in the therapy of $\mathrm{PH}$. Patients with noncirrhotic $\mathrm{PH}$, in particular, benefit from surgical portocaval shunts, which provide excellent secondary prophylaxis for VB but also prevent ongoing thrombosis of the portovenous system, i.e., "panthrombosis."

\section{Definition and Classification of PH}

Clinically significant $\mathrm{PH}$ is defined as a hepatic venous pressure gradient (HVPG) of $\geq 10 \mathrm{~mm} \mathrm{Hg}$ [6]. Above this value, gastroesophageal varices develop, and bleeding occurs at $12 \mathrm{~mm} \mathrm{Hg}$ [2]. The leading cause for PH in Western countries is liver cirrhosis (90\%), predominantly caused by alcoholic liver disease and viral hepatitis. Less common is extrahepatic PVT (8-10\%) in which liver function is normally not impaired [2]. Rare causes are posthepatic disorders like Budd-Chiari syndrome [21]. Complications from $\mathrm{PH}$ in cirrhosis like ascites, bacterial peritonitis, hepatorenal syndrome, portopulmonary hypertension, hepatopulmonary syndrome, hepatic enzephalopathy, portal hypertensive gastropathy, enteropathy, colopathy, and the formation of esophagogastric varices dominate the further course of the disease [2]. Two-thirds of cirrhotic patients develop varices, with bleeding occurring in $30-40 \%$ of these patients [7]. The impairment in liver function dominates the outcome after the first bleeding episode; average mortality is $20-35 \%$ but can be as high as $50 \%$ in Child-Pugh class $C$ patients $[7,22,23]$. Impaired liver function also increases the risk of early rebleeding [23].

In cases of noncirrhotic PH due to PVT, it is important to determine the stage of PVT (recent vs. chronic), which can sometimes be difficult. Recent PVT can be assumed when patients present with symptoms like abdominal pain, ascites or fever in the absence of portosystemic collaterals, or portal cavernoma. The initial phase of chronic PVT can be asymptomatic, and the disease and its underlying factors are often not diagnosed until the first bleeding episode [14].

Update on Shunt Surgery

\section{Diagnostics}

Aside from the underlying disease (liver function?), the extent of PVT is crucial for the planning of a surgical therapy. Medical history includes the typical complications of $\mathrm{PH}$ and the history of gastrointestinal hemorrhages. Upper gastrointestinal endoscopy can diagnose esophagogastric varices and exclude other sources of gastrointestinal bleeding. Bleeding risk is classified by the localization, size, color, and stigmata of the varices [7]. The exact quantification of liver function is crucial for the following therapy. Child-Pugh class, MELD score, and transient elastography $\left(\right.$ Fibroscan $\left.\left.^{\circledR}\right)[24,25]\right)$ can assess the severity of liver fibrosis/cirrhosis, and in special cases, liver biopsy can provide histological information [26]. In known cirrhosis, new-onset PVT should lead to imaging combined with $a$-fetoprotein levels to exclude hepatocellular carcinoma formation. Especially in noncirrhotic $\mathrm{PH}$, a hypercoagulable syndrome or myeoloproliferative neoplasm must be evaluated. This includes measurements of protein $\mathrm{C}$, protein $\mathrm{S}$, antithrombin III, total homocysteine serum levels, anti-cardiolipin antibodies, lupus-like anticoagulant, and anti- $\beta_{2}$ glycoprotein antibodies [27]. Genetic studies for factor $V$ Leiden, prothrombin G20210A, and JAK2 gene mutations should be conducted, and bone marrow biopsy can be useful $[28,29]$. Abdominal sonography is the first-line imaging technique for the diagnosis of cirrhosis and PVT, with a high sensitivity. In compensated patients, sensitivity for $\mathrm{PH}$ is lower, but indirect signs like splenomegaly or ascites can be detected [2]. CT and MRI (sometimes combined) are used to visualize the portal system including the extent of the PVT. They can also map the collateral circulation and identify rare causes for $\mathrm{PH}$ (inflammation or tumor growth) $[2,28]$. Visceral angiography is no longer standard, but can still be used in selected cases to assess the direction of blood flow and map collateral circulation precisely, in order to evaluate the feasibility of a selective surgical shunt [10].

\section{Indication for Portal Decompression}

There is no indication for prophylactic portal decompression (either TIPS or surgical shunt) in asymptomatic varices $[6,9,30,31]$. If VB occurs, the primary therapy is the combination of blood volume restitution, antibiotic prophylaxis if higher grade cirrhosis is present, vasoactive drugs (terlipressin, somatostatin, or octreotide), and endoscopy [6]. Emergency portal decompression is seldom indicated. Nonetheless, some groups report excellent outcomes with early TIPS [32], which is also recommended in the current Baveno consensus statement [6] for patients at a high risk of treatment failure (Child-Pugh class $\mathrm{C} / \mathrm{B}$ 


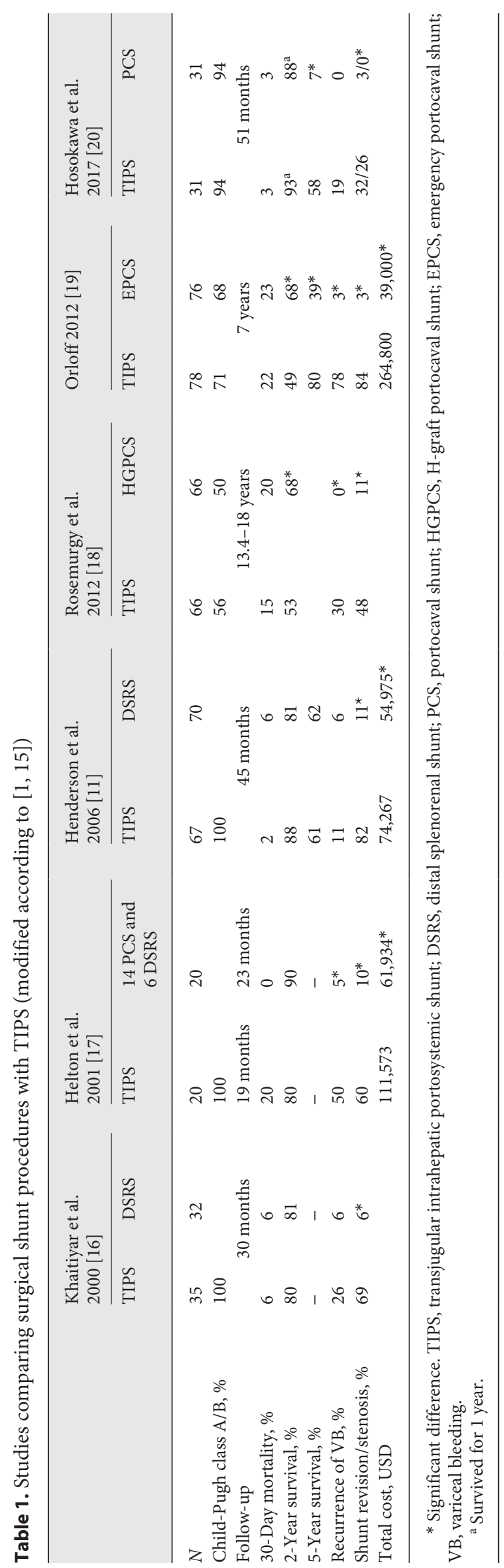

with active bleeding), or operative portocaval shunt procedures [19]. Initial treatment failure with rebleeding occurs in $20-30 \%$ [ $8-11]$. As stated earlier, the further therapy should be guided according to the hepatic reserve.

\section{Liver Cirrhosis}

Three factors should be included in the treatment decision: the hepatic reserve, imminent liver transplantation, and the morphology and patency of the portovenous system.

Operative decompression should only be undertaken in compensated liver function due to high procedural mortality in Child-Pugh class C patients of $>50 \%$ as well as high encephalopathy rates [14]. Of special importance for the preservation of liver function is the maintenance of at least a partial hepatopetal blood flow. If liver transplantation is planned, TIPS, with the possibility of avoiding an abdominal operation and preserving the hilar anatomy, is widely favored. Nevertheless, transplantation complications due to TIPS misplacement have been described [33]. In patients with failed TIPS, a distal splenorenal shunt can be applied without touching the hilar structures [34], or a mesocaval or mesorenal shunt should be used which can be easily ligated during tranplantation. Of course, the planned shunt procedure depends on the patency of the portomesenteric veins. Undoubtedly, liver transplantation is the only causal therapy for cirrhosis. But $20-30 \%$ of the patients suffering from variceal rebleeding have an excellent liver function and do not require transplantation [31]. These patients are now widely treated with TIPS as a bridging procedure to transplantation, but $<10 \%$ of patients are transplanted following TIPS $[35,36]$. According to the scientific evidence, surgical shunting procedures show a comparable or even better outcome in patients with good liver function (ChildPugh class A and B), but even after surgical shunt placement, liver transplantation is not more common $[37,38]$.

The portocaval $\mathrm{H}$-graft interposition shunt (SARFEH) is widely used to preserve a hepatopetal flow of about $80 \%$ due to the 8-mm diameter of the PTFE graft used [14]. The encephalopathy rate is low at only $5 \%$, and rebleeding occurs in 5\%, with a graft patency of about $95 \%$ over 7 years $[18,39]$. A selective decompression of the left upper quadrant can be achieved with the distal splenorenal shunt (WARREN), even if the portal and superior mesenteric vein are occluded. Hepatopetal flow is maintained in $70 \%$ of cases [14]. This shunt has a low rebleeding frequency of $5-8 \%$, a low mortality of $<5 \%$, and a 3 - to 5 -year survival rate of $75-80 \%$ [11]. Shunt occlusion occurs in $6-11 \%$ of patients $[11,16]$. It is of outmost importance to perform a complete splenopancreatic disconnenction, in order to prevent newly developing collateralization which can be technically demanding especially when pancreatitis is apparent $[10,34]$. 


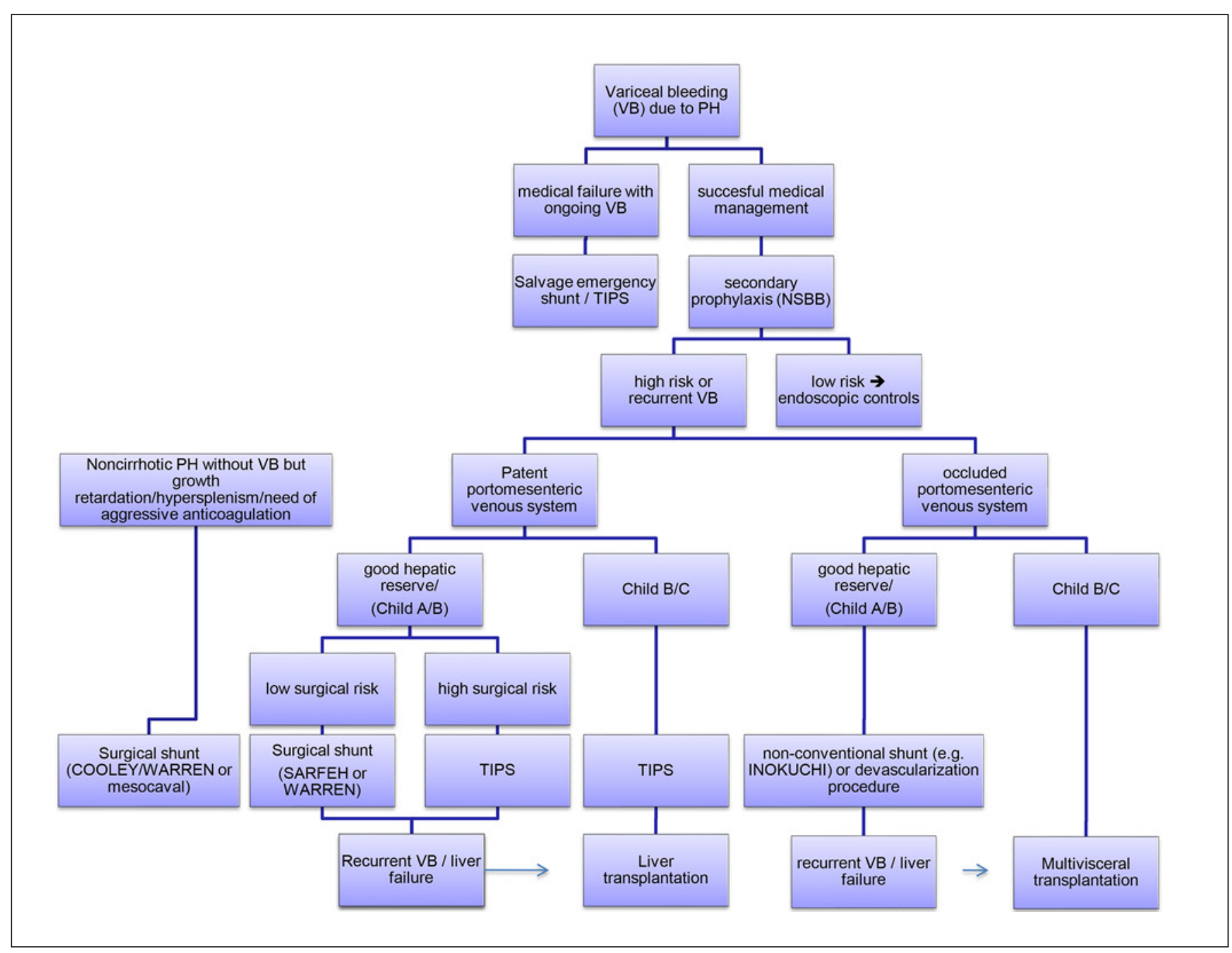

Fig. 1. Algorithm for the secondary prophylaxis of variceal bleeding (modified according to Glowka et al. [1]). NSBB, nonselective $\beta$-blockers; Child, Child-Pugh class.

\section{Noncirrhotic PVT}

The outcome for shunting procedures after VB without impaired liver function is better than in cirrhotic $\mathrm{PH}$, and late events like slow hepatic dysfunction and portal biliopathy can be avoided [40]. In children and young adults, particularly, other indications than the secondary prophylaxis of VB should be considered; hypersplenism, thrombocytopenia, and growth retardation are reasons for decompression of the portal system [40]. In recent PVT, the risk of ongoing thrombosis with intestinal infarction is as high as for $\mathrm{VB}$, with an appositional thrombus of the superior mesenteric vein and splanchnic vein present in $37 \%$ of cases [41]. In cases of chronic PVT, shunting provides a patent portovenous system in addition to rebleeding prophylaxis, allowing an aggressive anticoagulation therapy when there is a myeloproliferative neoplasm or hypercoagulable syndrome. PVT caused by malignant tumor growth (e.g., pancreatic cancer and hepatocellular car- cinoma) is not a good indication for surgical shunt placement due to the poor prognosis [14].

Patients with noncirrhotic PH can largely benefit from the splenorenal side-to-side shunt (COOLEY), especially if only a segmental PVT and a patent superior mesenteric vein are present. The procedure decompresses the gastroesophageal varices and mesenteric compartment, and also shows excellent patency $(87 \%)$ and a low rebleeding frequency (10\%) [42]. If selective decompression of the left upper quadrant is warranted, the WARREN shunt can also be used for noncirrhotic PVT. The mesocaval shunt is a small-diameter shunt and can be applied with or without PTFE interposition. Results differ, with a rebleeding rate of $5-15 \%$ and a patency of $81-95 \%[43,44]$. It is a good alternative in cases of noncirrhotic PVT and patent superior mesenteric vein when the splenic and portal veins are occluded.

Generally, the patency of the portovenus branches dictate the type of surgical shunt procedure in extrahepatic 
PVT. If the left gastric vein is patent, it can be anastomized with the inferior vena cava (the INOKUCHI shunt [45]). In cases of total occlusion of the portovenous system and recurrent $\mathrm{VB}$ with preserved liver function, a devascularization procedure can be performed with low rebleeding rates of $1.5-16 \%$ and a mortality rate of $4-22 \%$ $[34,46]$. In cases of combined total portovenous occlusion and parenchymal decompensation, liver transplantation with cavoportal hemitransposition or multivisceral transplantation should be considered [10].

The end-to-side portocaval shunt is a total portosystemic shunt with no remaining hepatopetal flow. Despite its high patency rate and excellent prevention of rebleeding $(<5 \%)$, it has a high rate of encephalopathy (approx. $40 \%)$ and is nowadays only used in emergency settings due to its easy technical feasibility [34, 47].

In the Baveno V consensus statement, PTFE-covered TIPS is the preferred therapy for patients failing medical treatment for the prevention of rebleeding. Surgical shunts are considered in Child-Pugh class A and B patients only if TIPS in unavailable [5]. The scientific basis for this decision is still lacking. Six studies (Table 1) have compared TIPS with surgical shunts. All these studies show comparable or better results for the surgical shunting procedures. In most studies, the cost-effectiveness of surgical shunt placement is better than that of TIPS, mostly because of the higher rate of reinterventions after TIPS. The common argument of a higher periprocedural mortality of surgery compared to TIPS can be contradicted with the 6 studies above. A German case series showed constantly better results for surgical shunts. There was a rebleeding rate of $10.5-30 \%$ for TIPS versus $1-11 \%$ for the surgical shunt, a reintervention rate of $48-82 \%$ (TIPS) versus $6.3-11 \%$ (surgical shunt), and a 30 -day-mortality of $15-40 \%$ (TIPS) versus $8-20 \%$ (surgical shunt) [15]. TIPS supporters criticized the fact that most of these trials used bare-metal TIPS rather than the PTFE-covered TIPS now in use. Hosokawa et al. [20] included PTFE-covered
TIPS in their study and also found better results with surgical shunts. Most studies evaluating PTFE-covered TIPS are retrospective, case series only, or have poor follow-up rates [40-43]. Findings for an overall survival benefit of PTFE-covered versus uncovered TIPS vary $[44,45]$. There are only a few studies on applying TIPS for noncirrhotic PVT, and they show a reintervention rate of 35\% [46]. In our opinion, the decompressive therapy for each patient suffering from $\mathrm{PH}$ should be planned by an interdisciplinary board.

\section{Conclusion}

VB is a severe complication of $\mathrm{PH}$, with a high mortality. The primary therapy is medical (including endoscopy), but when recurrent bleeding occurs an interdisciplinary approach should be followed. A team of gastroenterologists, interventional radiologists, and gastrointestinal surgeons should recommend a therapy that takes into account liver function, portovenous morphology, personal expertise, and the patient's preference (Fig. 1). Patients with noncirrhotic PVT, in particular, can benefit from the surgical shunt procedure.

\section{Disclosure Statement}

The authors have no conflicts of interest to declare.

\section{Funding Sources}

No funding was received.

\section{Author Contributions}

T.R.G. and S.M. did the literature search, interpreted the data, and drafted the manuscript. All 3 authors revised the draft critically and gave their final approval.

\section{References}

1 Glowka TR, Kalff JC, Schäfer N. Clinical Management of Chronic Portal/Mesenteric Vein Thrombosis: The Surgeon's Point of View. Viszeralmedizin. 2014 Dec;30(6):409-15.

2 Berzigotti A, Seijo S, Reverter E, Bosch J. Assessing portal hypertension in liver diseases. Expert Rev Gastroenterol Hepatol. 2013 Feb; 7:141-55

3 Okuda K, Ohnishi K, Kimura K, Matsutani S, Sumida M, Goto N, et al. Incidence of portal vein thrombosis in liver cirrhosis. An angiographic study in 708 patients. Gastroenterology. 1985 Aug;89:279-86.

4 Francoz C, Belghiti J, Vilgrain V, Sommacale D, Paradis V, Condat B, et al. Splanchnic vein thrombosis in candidates for liver transplantation: usefulness of screening and anticoagulation. Gut. 2005 May;54:691-7.

5 Amitrano L, Guardascione MA, Scaglione M, Pezzullo L, Sangiuliano N, Armellino MF, et al. Prognostic factors in noncirrhotic patients with splanchnic vein thromboses. Am J Gastroenterol. 2007 Nov; 102: 2464-70.

6 de Franchis R, Baveno VI; Baveno VI Faculty. Expanding consensus in portal hypertension: Report of the Baveno VI Consensus Workshop: stratifying risk and individualizing care for portal hypertension. J Hepatol. 2015 Sep; 63(3):743-52.
7 Jensen DM. Endoscopic screening for varices in cirrhosis: findings, implications, and outcomes. Gastroenterology. 2002 May; 122: 1620-30.

8 Sharara AI, Rockey DC. Gastroesophageal variceal hemorrhage. N Engl J Med. 2001 Aug;345:669-81.

9 D’Amico G, Pagliaro L, Bosch J. The treatment of portal hypertension: a meta-analytic review. Hepatology. 1995 Jul;22:332-54.

10 Costa G, Cruz RJ Jr, Abu-Elmagd KM. Surgical shunt versus TIPS for treatment of variceal hemorrhage in the current era of liver and multivisceral transplantation. Surg Clin North Am. 2010 Aug;90:891-905. 
11 Henderson JM, Boyer TD, Kutner MH, Galloway JR, Rikkers LF, Jeffers LJ, et al. Distal splenorenal shunt versus transjugular intrahepatic portal systematic shunt for variceal bleeding: a randomized trial. Gastroenterology. 2006 May;130:1643-51.

12 Rossle M. TIPS: 25 years later. J Hepatol. 2013 Nov;59:1081-93.

13 Rosemurgy AS, Molloy DL, Thometz DP, Villadolid DV, Cowgill SM, Zervos EE. TIPS in Florida: is its application a result of evidencebased medicine? J Am Coll Surg. 2007 May; 204:794-801.

14 Wolff M, Hirner A. Surgical treatment of portal hypertension. Zentralbl Chir. 2005 Jun; 130:238-45. German.

15 Puhl G, Gul S, Neuhaus P. Portosystemic shunt surgery between TIPS and liver transplantation. Chirurg. 2011 Oct;82:898-905. German.

16 Khaitiyar JS, Luthra SK, Prasad N, Ratnakar N, Daruwala DK. Transjugular intrahepatic portosystemic shunt versus distal splenorenal shunt - a comparative study. Hepatogastroenterology. 2000 Mar;47:492-7.

17 Helton WS, Maves R, Wicks K, Johansen K. Transjugular intrahepatic portasystemic shunt vs surgical shunt in good-risk cirrhotic patients: a case-control comparison. Arch Surg. 2001 Jan;136:17-20.

18 Rosemurgy AS, Frohman HA, Teta AF, Luberice K, Ross SB. Prosthetic H-graft portacaval shunts vs transjugular intrahepatic portasystemic stent shunts: 18-year follow-up of a randomized trial. J Am Coll Surg. 2012 Apr; 214:445-53.

19 Orloff MJ. Fifty-three years' experience with randomized clinical trials of emergency portacaval shunt for bleeding esophageal varices in Cirrhosis: 1958-2011. JAMA Surg. 2014 Feb;149:155-69.

20 Hosokawa I, Adam R, Allard MA, Pittau G, Vibert E, Cherqui D, et al. Outcomes of surgical shunts and transjugular intrahepatic portasystemic stent shunts for complicated portal hypertension. Br J Surg. 2017 Mar;104(4): 443-51.

21 Darwish MS, Plessier A, Hernandez-Guerra M, Fabris F, Eapen CE, Bahr MJ, et al. Etiology, management, and outcome of the BuddChiari syndrome. Ann Intern Med. 2009 Aug; 151:167-75.

22 Graham DY, Smith JL. The course of patients after variceal hemorrhage. Gastroenterology. 1981 Apr;80:800-9.
23 D'Amico G, de FR. Upper digestive bleeding in cirrhosis. Post-therapeutic outcome and prognostic indicators. Hepatology. 2003 Sep; 38:599-612.

24 Kamath PS, Wiesner RH, Malinchoc M, Kremers W, Therneau TM, Kosberg CL, et al. A model to predict survival in patients with endstage liver disease. Hepatology. 2001 Feb;33: 464-70.

25 Castera L, Pinzani M, Bosch J. Non-invasive evaluation of portal hypertension using transient elastography. J Hepatol. 2012 Mar;56: 696-703.

26 Rockey DC, Caldwell SH, Goodman ZD, Nelson RC, Smith AD. Liver biopsy. Hepatology. 2009 Mar;49:1017-44.

27 Trebicka J, Strassburg CP. Etiology and Complications of Portal Vein Thrombosis. Viszeralmedizin. 2014 Dec;30(6):375-80.

28 Primignani M. Portal vein thrombosis, revisited. Dig Liver Dis. 2010 Mar;42:163-70.

29 Valla DC, Condat B. Portal vein thrombosis in adults: pathophysiology, pathogenesis and management. J Hepatol. 2000 May;32:86571.

30 Burroughs AK, Mezzanotte G, Phillips A, McCormick PA, McIntyre N. Cirrhotics with variceal hemorrhage: the importance of the time interval between admission and the start of analysis for survival and rebleeding rates. Hepatology. 1989 Jun;9:801-7.

31 Rikkers LF, Jin G, Langnas AN, Shaw BW Jr. Shunt surgery during the era of liver transplantation. Ann Surg. 1997 Jul;226:51-7.

32 Garcia-Pagan JC, Caca K, Bureau C, Laleman W, Appenrodt B, Luca A, et al. Early use of TIPS in patients with cirrhosis and variceal bleeding. N Engl J Med. 2010 Jun;362:2370-9.

33 Clavien PA, Selzner M, Tuttle-Newhall JE, Harland RC, Suhocki P. Liver transplantation complicated by misplaced TIPS in the portal vein. Ann Surg. 1998 Mar;227:440-5.

34 Rosemurgy AS, Zervos EE. Management of variceal hemorrhage. Curr Probl Surg. 2003 Jun;40:263-343.

35 Charon JP, Alaeddin FH, Pimpalwar SA, Fay DM, Olliff SP, Jackson RW, et al. Results of a retrospective multicenter trial of the Viatorr expanded polytetrafluoroethylene-covered stent-graft for transjugular intrahepatic portosystemic shunt creation. J Vasc Interv Radiol. 2004 Nov; 15:1219-30.
36 Tripathi D, Helmy A, Macbeth K, Balata S, Lui HF, Stanley AJ, et al. Ten years' follow-up of 472 patients following transjugular intrahepatic portosystemic stent-shunt insertion at a single centre. Eur J Gastroenterol Hepatol. 2004 Jan;16:9-18.

37 Orloff MJ, Orloff MS, Girard B, Orloff SL. When is liver transplant indicated in cirrhosis with bleeding varices? Transplant Proc. 2001 Feb;33:1366.

38 Henderson JM, Nagle A, Curtas S, Geisinger M, Barnes D. Surgical shunts and TIPS for variceal decompression in the 1990s. Surgery. 2000 Oct;128:540-7.

39 Rosemurgy AS, Bloomston M, Clark WC, Thometz DP, Zervos EE. H-graft portacaval shunts versus TIPS: ten-year follow-up of a randomized trial with comparison to predicted survivals. Ann Surg. 2005 Feb;241:238-46.

40 Khanna R, Sarin SK. Non-cirrhotic portal hypertension - diagnosis and management. J Hepatol. 2014 Feb;60:421-41.

41 Condat B, Pessione F, Helene DM, Hillaire S, Valla D. Recent portal or mesenteric venous thrombosis: increased recognition and frequent recanalization on anticoagulant therapy. Hepatology. 2000 Sep;32:466-70.

42 Mitra SK, Rao KL, Narasimhan KL, Dilawari JB, Batra YK, Chawla Y, et al. Side-to-side lienorenal shunt without splenectomy in noncirrhotic portal hypertension in children. J Pediatr Surg. 1993 Mar;28:398-401.

43 Mercado MA, Orozco H, Guillen-Navarro E, Acosta E, Lopez-Martinez LM, Hinojosa C, et al. Small-diameter mesocaval shunts: a 10year evaluation. J Gastrointest Surg. 2000 Sep; 4:453-7.

44 Paquet KJ, Lazar A, Koussouris P, Hotzel B, Gad HA, Kuhn R, et al. Mesocaval interposition shunt with small-diameter polytetrafluoroethylene grafts in sclerotherapy failure. $\mathrm{Br} J$ Surg. 1995 Feb;82:199-203.

45 Inokuchi K, Kobayashi M, Ogawa Y, Saku M, Nagasue N. Results of left gastric vena caval shunt for esophageal varices: analysis of one hundred clinical cases. Surgery. 1975 Nov; 78(5):628-36

46 Orozco H, Mercado MA, Takahashi T, Hernandez-Ortiz J, Capellan JF, Garcia-Tsao G. Elective treatment of bleeding varices with the Sugiura operation over 10 years. Am J Surg. 1992 Jun;163:585-9.

47 Wolff M, Kalff JC, Textor J, Hirner A. Surgery for portal hypertension and transjugular intrahepatic portosystemic shunts in Germany: results of a national survey. Chirurg. 1999 Apr;70:447-52 